\title{
Flow visualisation and modelling of solid soap extrusion
}

\author{
M. P. Bryan, S. L. Rough, D. I. Wilson* \\ Department of Chemical Engineering and Biotechnology, University of Cambridge, Philippa \\ Fawcett Drive, Cambridge, CB3 OAS, UK
}

\begin{abstract}
Ram extrusion of a solid granular soap was studied using three geometrically identical but differently-scaled extruders. The experimental design revealed deviation from the Benbow and Bridgwater (1993) extrusion model due to nonideal, scale-dependent effects. Typically these effects, linked to the shear rate in the extruder, are absorbed into the model's material pseudo-properties. The data were able to be represented using the Basterfield et al. (2005) model for extrusion flow which does include a shear rate as a variable.

Flow visualisation in conjunction with fluid dynamics-based simulations showed, however, that the assumptions underlying the Basterfield et al. model are not appropriate for soap extrusion, despite the good agreement of the model with the experimental extrusion data. This highlights a need for care in interpretation of extrusion data, in that the limited information gathered about any given experiment, typically just the extrusion pressure, can lead to the generation of spurious parameters if the wrong model is applied.

Keywords: extrusion, viscoplastic, flow visualisation, modelling
\end{abstract}

\section{Introduction}

Extrusion is a net shape forming operation for the manufacture of objects with a constant cross section. The material to be formed is forced under pressure through an orifice or die with the desired shape, after which the rheological

\footnotetext{
*Corresponding author, diw11@cam.ac.uk, +44(0)1223 334791
} 
5 properties of the material cause it to retain its new geometry. Ram extrusion is a type of extrusion in which a moving piston or ram directly drives the material through the die while the material is constrained in a reservoir (the barrel).

The classes of extrudable materials are varied, ranging from liquid polymer melts, which rely on post-processing solidification and their high viscosity to retain the die shape; to metals such as aluminium which deform elasto-plastically when changing shape. This work is concerned with the ram extrusion of soft solids and visco-plastic fluids, such as gels, dense solid-liquid suspensions and pastes, which have applications in ceramic manufacturing, pharmaceuticals and foodstuffs, among other areas (Wilson and Rough, 2006).

Analysis of extrusion flow is complex, owing to a combination of the nontrivial contraction flow field, materials with strongly non-Newtonian rheology (particularly in extension) and the phenomenon of wall slip, which is especially prevalent in dense solid-liquid suspensions (Barnes, 1995). As a result, there is a gap in knowledge between theoretical models of extrusion and the issues encountered in real-world manufacture.

A popular model for ram extrusion of such materials is that of Benbow and Bridgwater (1993), equation 1a. The model, proposed by Ovenston and Benbow (1968), and later advanced by Benbow (1971) and Benbow et al. (1987), describes the extrusion pressure $P_{\mathrm{ex}}$, which is the force applied to the material 25 divided by the contact area of the ram, as a function of the extrusion geometry and rate, these being defined in figure 1 for a cylindrical extruder. The type of extruder shown is known as a square-entry device as the angle between the barrel wall and the surface of the die is $90^{\circ}$; an alternative style of extruder is a conical-entry device (not shown) where the die is tapered and the angle at this corner is greater than $90^{\circ}$.

The contributions to $P_{\mathrm{ex}}$ for the square-entry case according to the model are the pressure required to affect the change in cross-sectional area from the barrel to the die $\left(P_{1}\right)$ and the pressure to overcome friction between the die walls and the material $\left(P_{2}\right)$. Material both upstream and downstream of the die is assumed 35 to be in plug flow, with the ram velocity $\left(V_{\text {ram }}\right)$ being related to the extrudate 


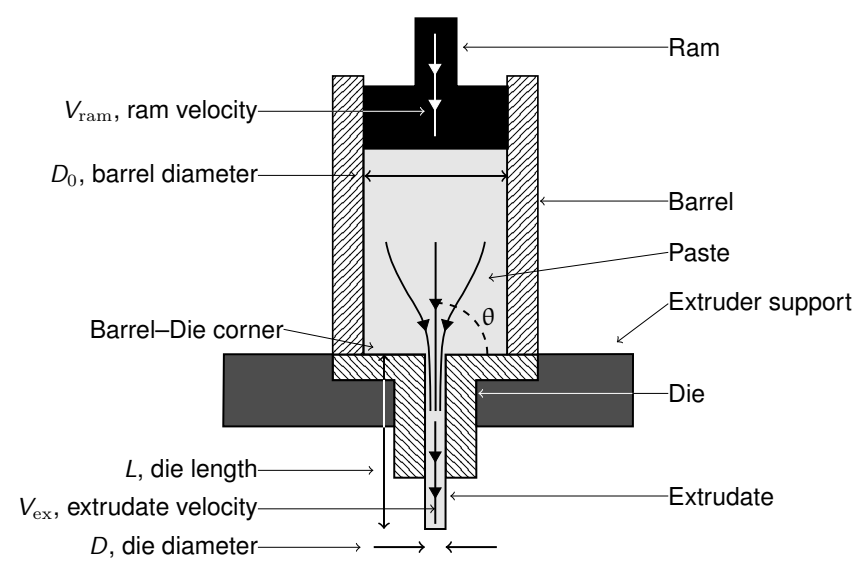

Figure 1: Schematic diagram of a vertical, concentric cylinder ram extruder with a squareentry geometry.

velocity in the die $\left(V_{\mathrm{ex}}\right)$ by conservation of volume, i.e. $D_{0}^{2} V_{\mathrm{ram}}=D^{2} V_{\mathrm{ex}}$.

$$
\begin{aligned}
P_{\mathrm{ex}} & =\underbrace{2 \sigma_{\mathrm{Y}} \ln \frac{D_{0}}{D}}_{P_{1}}+\underbrace{4 \tau_{\mathrm{W}} \frac{L}{D}}_{P_{2}} \\
& =2\left(\sigma_{0}+\alpha V_{\mathrm{ex}}^{m}\right) \ln \frac{D_{0}}{D}+4\left(\tau_{0}+\beta V_{\mathrm{ex}}^{n}\right) \frac{L}{D}
\end{aligned}
$$

While the $P_{1}$ contribution is derived from an assumption of ideal work on a perfectly plastic material (with yield stress $\sigma_{\mathrm{Y}}$ ), real extrusion materials are more complex. Experimental observations caused Benbow and Bridgwater to account for non-ideal work using the modified yield stress expression $\sigma_{0}+\alpha V_{\mathrm{ex}}^{m}$, as in equation 1b. Here $\sigma_{0}$ is an 'ideal' static yield stress, $\alpha$ is a velocity multiplier for additional yield strength and $m$ is a velocity exponent.

The $P_{2}$ contribution is the result of a force balance on the paste which experiences a shear stress from the die wall $\left(\tau_{\mathrm{W}}\right)$. This was again extended based on experimental observations (equation 1b) to include a rate-dependent wall shear stress $\left(\tau_{0}+\beta V_{\text {ex }}^{n}\right)$, with a 'slip yield stress' $\tau_{0}$ and an additional multiplier and exponent $\beta$ and $n$. This form of wall shear stress is similar to the slip law attributed to Navier (1823), with an extension to non-linearity and allowance for cessation of wall slip below a certain stress. 
An alternative $P_{1}$ expression was provided by Basterfield et al. (2005), equations $2 \mathrm{a}$ and $2 \mathrm{~b}$, which is based on an analysis of a material exhibiting HerschelBulkley rheology. The analysis assumes a conically converging flow of material into the die, forming a conical flow zone with half-angle $\theta$ measured from the centreline (also defined in figure 1 for the square-entry case). This type of model is referred to in the literature as a 'radial flow' model, examples being Snelling and Lontz (1960) and Ariawan et al. (2002), among others, as the flow converges radially to a point just inside the die entrance.

$$
\begin{aligned}
& P_{1}=2 \sigma_{\mathrm{Y}, \mathrm{HB}} \ln \frac{D_{0}}{D}+A k_{\mathrm{HB}}\left(\frac{2 V_{\mathrm{ex}}}{D}\right)^{h}\left[1-\left(\frac{D}{D_{0}}\right)^{3 h}\right] \\
& A=\frac{2}{3 h}[\sin \theta(1+\cos \theta)]^{h}
\end{aligned}
$$

50 A conical flow field is assumed to develop either due to the use of a conical-entry extruder as described earlier, or in the square-entry case due to material at the barrel-die corners being stagnant and unyielded, forming static regions which emulate a conical wall. A further assumption of the model is that this wall is frictionless, which is required to permit the derivation of this one dimensional 55 result.

In contrast to the Benbow-Bridgwater model, which uses phenomenological material parameters, the Basterfield et al. model contains the Herschel-Bulkley yield stress $\sigma_{\mathrm{Y}, \mathrm{HB}}$, the viscosity coefficient $k_{\mathrm{HB}}$ and the viscosity exponent $h$. This allows material data derived from alternative sources (such as rheometric tests) to be applied to ram extrusion modelling, and vice versa.

Other authors have also proposed theoretical models for the $P_{1}$ term, typically reliant on a similar assumption of directly converging flow. Examples include Ariawan et al. (2002) for a poly-tetrafluoroethylene resin and Althaus and Windhab (2011) for a highly unsaturated wet powder, who used a granular solids-modelling approach. The need to develop bespoke extrusion models for specific materials highlights the complexities and range of behaviours found in soft-solid flow, and should demonstrate the need for caution when applying any 'simple' model. 
Many attempts have also been made to analyse extrusion through numerical

2009; Kountouriotis et al., 2014). These, however, share the same limitations as theoretical treatments, as they must at some point select a material and wall interaction model to represent the complex real system.

The most common approach is to treat the extruding material as a reguHerschel-Bulkley material but with a divergent viscosity near the yield point, rather than true yielding. This modification is a mathematical convenience to allow simulation using standard fluid dynamics solvers, though techniques do exist to allow the true form of the material models to be used (Saramito and so Roquet, 2001; Moyers-Gonzalez and Frigaard, 2004; Dimakopoulos et al., 2013) at the price of increased computational time and implementation complexity.

Less common, but perhaps more suitable for particularly dry or stiff materials, is a treatment involving solid mechanics. Horrobin and Nedderman (1998) and Horrobin (1999) simulated an elastic-plastic solid using both no-slip, partial slip and frictionless walls. Their data provide a correlation for $P_{1}$ for the no-slip case given by:

$$
P_{1}=1.92 \sigma_{\mathrm{Y}} \ln \frac{D_{0}}{D}+1.08 \sigma_{\mathrm{Y}}
$$

where the similarity to both the Benbow-Bridgwater and Basterfield et al. models can be seen. However, the use of an elastic-plastic model without rate dependence implies no scaling with $V_{\text {ex }}$, despite experimental observations to support this. Beyond this there has to the best of our knowledge been limited work done modelling soft-solid extrusion using solid mechanics solvers, although a notable example is that of Patel et al. (2007, 2017).

An additional factor that feeds uncertainty over selection of an extrusion model is that most extrusion experiments only record the extrusion pressure $P_{\mathrm{ex}}$ 90 as a function of extrusion velocity and extruder geometry. Most models contain sufficient parametric degrees of freedom to enable these data to be represented, regardless of whether the choice of model is appropriate. 
Flow visualisation offers a possible source of supplemental validation, as it provides detailed information about flow velocities which can be compared to numerical solutions or assumed velocity profiles. Examples of flow visualisation as applied to extrusion include Götz et al. (1993) and Barnes et al. (2006) who used MRI to track paste movement, and Wildman et al. (1999) who used positron emission particle tracking. Several authors have also carried out a simpler visualisation process by marking areas of paste before extrusion, and subsequently examining any deformation of these regions to identify static or fast-flowing areas in the barrel. This can serve as a check on the assumed flow field. Examples of this include work by Ariawan et al. (2002), Perrot et al. (2007, 2012) and Bryan et al. (2015).

The current work presents laboratory-scale ram extrusion studies of a model solid granular soap with the aim of identifying an appropriate extrusion model. Also presented are data from a bespoke flow visualisation tool for ram extrusion, again using soap as the test material, in order to determine whether the radial flow hypothesis used in the Basterfield et al. (2005) model is applicable to soap. The results are then compared with fluid dynamics-based simulations of the same flow for the purposes of validation and as a further check on the choice of models.

\section{Materials and methods}

A dry, granular, solid soap used for commercial and domestic cleaning was selected as the experimental material. Soap extrusion has previously been studied by Amarasinghe and Wilson (1998), Domanti and Bridgwater (2000), Barnes et al. (2006) and Castro et al. (2010), and was found to behave reproducibly. The granules (Dri-Pak Ltd, UK) are translucent, cream-coloured and are typically square or diamond shaped with side length $5 \mathrm{~mm}$ and thickness $1 \mathrm{~mm}$. They are individually brittle but compact to a solid block under sufficient applied stress. The material was found to extrude reliably into smooth-sided, strong extrudates. The soap composition was not investigated in detail, though the manufacturer indicates that it is produced from a blend of sunflower and 
Table 1: Summary of barrel and die geometries

\begin{tabular}{llll}
\hline$D_{0}(\mathrm{~mm})$ & 25 & 11 & 5.5 \\
\hline$D(\mathrm{~mm})$ & 4.5 & 2.0 & 1.0 \\
$D_{0} / D(-)$ & 5.56 & 5.50 & 5.50 \\
$L / D(-)$ & $1.78,4,8,12$ & $2,4,8,12$ & $2,4,8,12$ \\
\hline
\end{tabular}

coconut oils. It is also possible to deduce that the soap is primarily sodium stearate (rather than a potassium or magnesium stearate) due to the brittleness of the granules (Barel et al., 2005, p. 488).

Most extrusions were carried out using three stainless steel, concentriccylinder, square-ended barrel and die sets, all axisymmetric, summarised in table 1 . The sets had the same ratio of $D_{0} / D$ for each extruder (within practical limits) as well as equivalent $L / D$ ranges, such that all geometric terms within the Benbow-Bridgwater model were kept constant. Each extrusion system was machined to a similar surface finish, and each set has experienced a similar degree of use such that any wear on the surfaces would be comparable.

Each barrel and die set was paired with a polyetherether ketone tipped stainless steel ram, machined to give a close fit to its particular barrel. Each set was mounted in a Zwick-Roell Z050 universal testing machine (Zwick GmbH, Germany) capable of exerting up to $50 \mathrm{kN}$ on the billet of material. The positioning resolution of the Zwick device was $1 \mu \mathrm{m}$ and the force sensor resolution was 0.1 N.

Each barrel was filled by hand such that the aspect ratio of the loaded billet (height/diameter) was approximately 6.5. After loading, each billet was compacted mechanically to the same applied pressure of $10 \mathrm{MPa}$ in order to minimise the presence of air pockets in the billet before extrusion. Extrudate velocities of $10,50,100,180$ and $250 \mathrm{~mm} / \mathrm{s}$ were used.

A windowed, hemicylindrical, stainless steel extruder was also designed and constructed to enable flow visualisation studies, shown in an expanded diagram in figure 2. The hemicylindrical barrel is of diameter $25 \mathrm{~mm}$ and the die of 


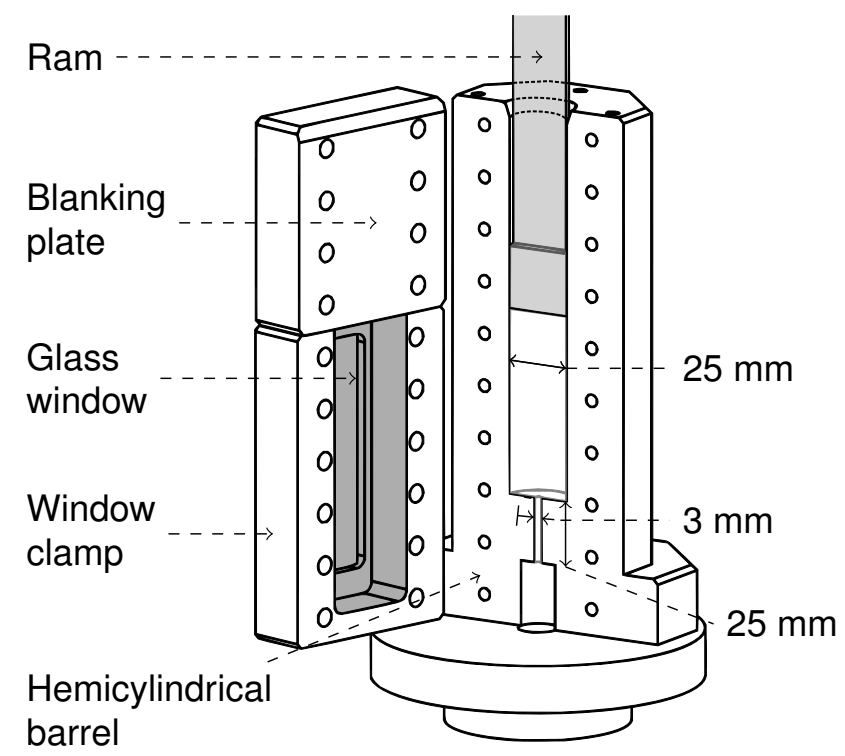

Figure 2: Expanded diagram of the hemicylindrical flow visualisation tool. In operation the blanking plate, glass window and clamp are rotated to lie flush with the barrel, and bolted in place.

diameter $3 \mathrm{~mm}$ with length $L=25 \mathrm{~mm}$. The upper $80 \mathrm{~mm}$ of the half-barrel is covered with a solid steel blanking plate, while a quartz glass window of thickness $19 \mathrm{~mm}$ and length $110 \mathrm{~mm}$ covers the remainder of the barrel, the die and a short distance beyond the die exit. A conical-shaped stainless steel insert was also fabricated, which converts the square-entry extruder into a conical-entry device with a half angle, $\theta$, of $30^{\circ}$ as defined in figure 1 .

The flow was visualised by seeding the soap granules with hard, black basalt spheres of typical diameter $250 \mu \mathrm{m}$ (Whitehouse Scientific Ltd, UK) and recording the motion of these particles through the window using a Nikon D3300 SLR camera coupled to a $40 \mathrm{~mm}$ focal length macro lens. These videos were then processed using a custom software routine written in MATLAB ${ }^{\mathrm{TM}}$ (The MathWorks Inc., USA). The routine detects each basalt sphere in each frame of the video, and through a combination of nearest-neighbour matching and extrapolation of prior trajectory constructs particle tracks through the field of the image. A Kalman filtering stage is then used to reduce noise in the data, simultaneously 
computing the particle velocities for analysis.

Separately, additional information about the flow pattern was ascertained by extruding a billet of soap through the cylindrical extruder in which part of the material had been stained black using graphite powder at a concentration of $1 \%$ by weight. The technique is referred to as contrasting paste extrusion and is described in more detail in Bryan et al. (2015) using a damp microcrystalline cellulose paste as the extrusion material.

Simulations of the extrusion flow were performed using ANSYS Polyflow 14.5 (ANSYS Inc., USA), a finite element-based fluid dynamics software package designed for non-Newtonian fluids. The Papanastasiou (1987) regularised viscosity model was used to simulate the visco-plastic behaviour (of the Herschel-Bulkley type), while a non-linear Navier-type slip law (equation 4) was used to describe the wall interaction behaviour, relating wall shear stress $\tau_{\mathrm{W}}$ to the slip velocity, here equivalent to $V_{\mathrm{ex}}$, through a slip coefficient and exponent $\beta$ and $n$.

$$
\tau_{\mathrm{W}}=\beta V_{\mathrm{ex}}^{n}
$$

The parameters for the wall interaction behaviour were determined through separate experiments conducted by the author (Bryan et al., 2017), with values of $\beta=4.8 \times 10^{5} \mathrm{~Pa} /(\mathrm{m} / \mathrm{s})^{0.34}$ and $n=0.34$ chosen as representative of the results seen experimentally. This model does not include a slip yield stress, viz. $\tau_{0}$, as in the Benbow-Bridgwater model (equation $1 \mathrm{~b}$ ); this is a limitation of the finite element solver used.

In other aspects the details of the simulations were similar to those reported in Bryan et al. (2015).

\section{Results and discussion}

\subsection{Extrusion data}

Under the Benbow-Bridgwater interpretation of extrusion data (equation $1 \mathrm{~b})$, for a given $D_{0} / D$ ratio and extrudate velocity $V_{\mathrm{ex}}$, the extrusion pressure should vary only as a linear function of the die aspect ratio $(L / D)$. The extrusion 
equipment was specifically chosen to give a near constant $D_{0} / D$ for the three sizes of barrel $\left(D_{0}=25,11,5.5 \mathrm{~mm}\right)$. Bagley-type plots recorded at an extrudate velocity of $100 \mathrm{~mm} / \mathrm{s}$ are shown in figure 3 .

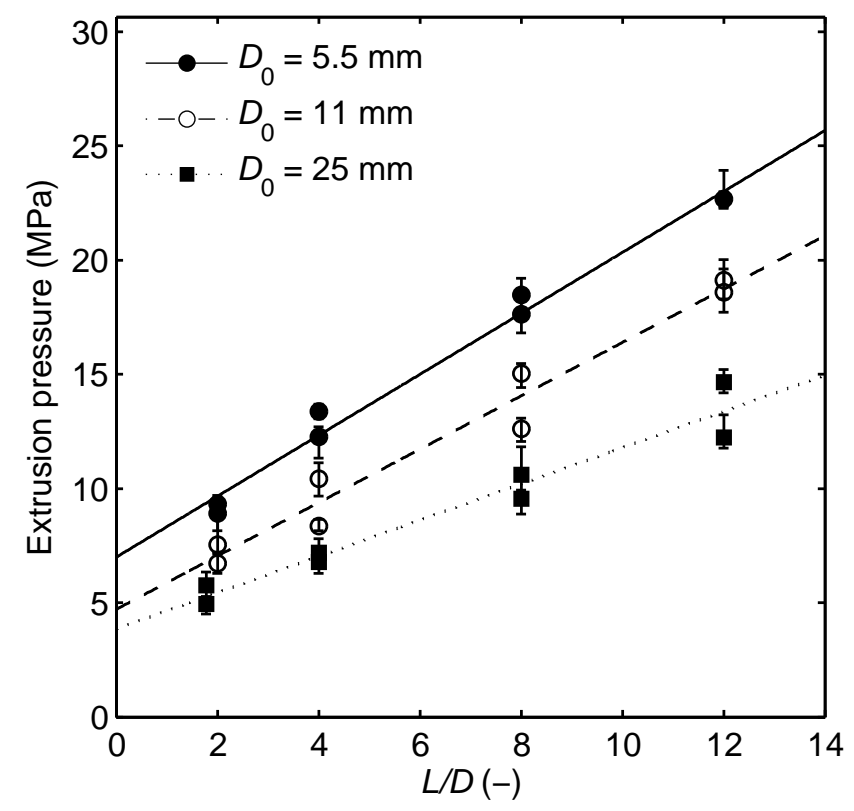

Figure 3: Bagley-type plots of soap extrusion in three geometrically identical, different-sized extruders at $V_{\mathrm{ex}}=100 \mathrm{~mm} / \mathrm{s}$. Straight lines are least squares best fits to the data, and error bars represent the 10th and 90th percentiles of extrusion pressure as sampled.

The data show a clear deviation from the Benbow-Bridgwater framework. The ordinate axis-intercept and slope of each line increase as $D_{0}$ and $D$ decrease. These are used to calculate the material yield stress $\left(\sigma_{\mathrm{Y}}\right)$ and the die wall shear stress $\left(\tau_{\mathrm{W}}\right)$, respectively. This trend was found to be consistent across the whole range of extrusion velocities studied and is summarised in figure 4 . In addition, values of the Benbow-Bridgwater parameters for different soaps from the literature are presented in table 2. The same trend was also recorded using an alternative material, a micro-crystalline cellulose and water paste (data provided as supplementary material).

The apparent variation of yield stress with scale is likely due to differences in the apparent shear rates in each extruder. This is expected to scale with the 


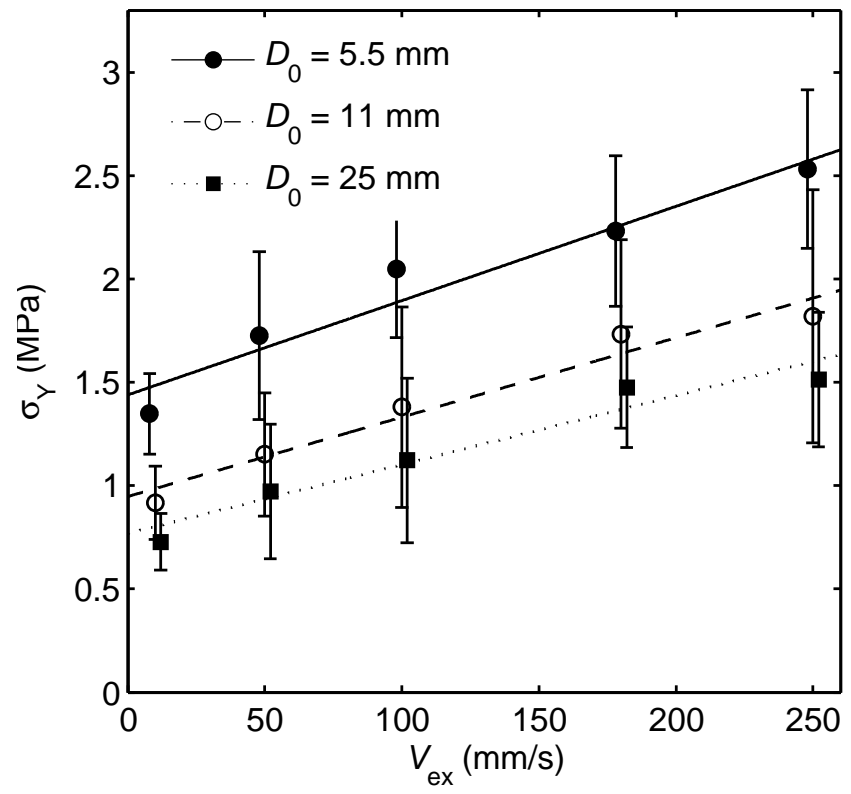

(a)

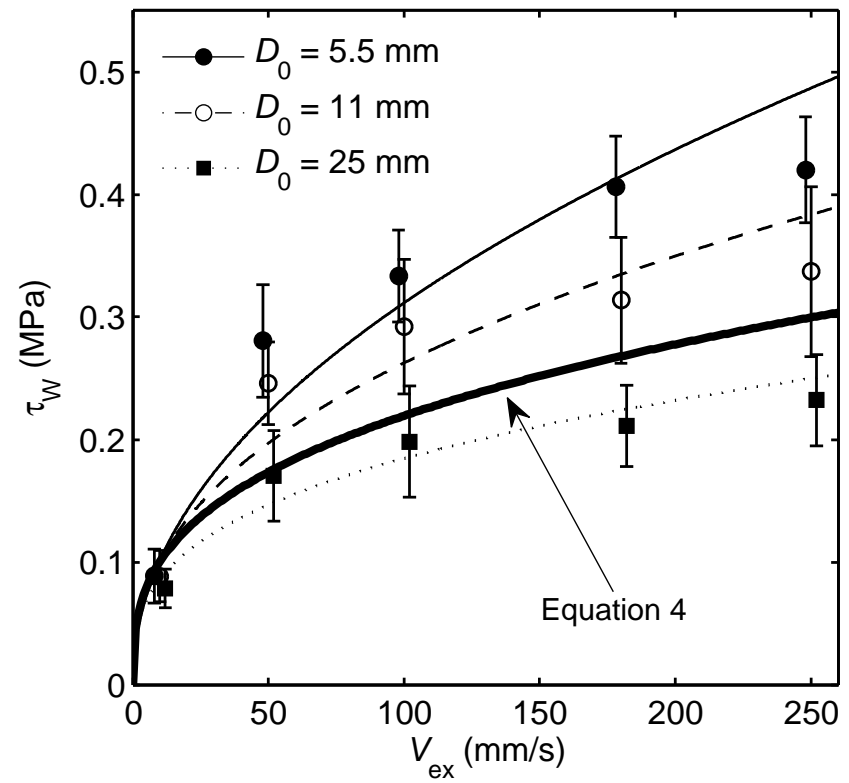

(b)

Figure 4: Benbow-Bridgwater parameters for soap, (a) yield stress and (b) wall shear stress, in three sizes of extruder. Lines are least-squares best fits to the data with parameters given in table 2. Error bars represent $90 \%$ confidence interval for the Bagley-type plot intercepts and slopes. Points are offset along the velocity axis for clarity. In figure 4(b) the additional thick line is equation 4 evaluated with the parameters used in later numerical simulations. 
Table 2: Parameters of the Benbow-Bridgwater model (equation 1b) obtained for soap in the three extruders tested and for different soaps from the literature.

\begin{tabular}{|c|c|c|c|c|c|c|c|c|}
\hline & $\begin{array}{l}D_{0} \\
(\mathrm{~mm})\end{array}$ & $\begin{array}{l}D \\
(\mathrm{~mm})\end{array}$ & $\begin{array}{l}\sigma_{0} \\
(\mathrm{MPa})\end{array}$ & $\begin{array}{l}\alpha \\
(\mathrm{MPa} / \\
\left.(\mathrm{mm} / \mathrm{s})^{-m}\right)\end{array}$ & $\begin{array}{l}m \\
(-)\end{array}$ & $\begin{array}{l}\tau_{0} \\
(\mathrm{MPa})\end{array}$ & $\begin{array}{l}\beta \\
(\mathrm{MPa} / \\
\left.(\mathrm{mm} / \mathrm{s})^{-n}\right) \\
\end{array}$ & $\begin{array}{l}n \\
(-)\end{array}$ \\
\hline Current & 25 & 4.5 & 0.77 & 0.0033 & 1 & 0 & 0.040 & 0.33 \\
\hline Current & 11 & 2 & 0.95 & 0.0038 & 1 & 0 & 0.039 & 0.41 \\
\hline Current & 5.5 & 1 & 1.44 & 0.0046 & 1 & 0 & 0.033 & 0.49 \\
\hline $\begin{array}{l}\text { Amarasinghe and } \\
\text { Wilson (1998) }\end{array}$ & 25 & 3 & 0.558 & 0.0039 & 0.87 & 0.018 & 0.011 & 0.56 \\
\hline $\begin{array}{l}\text { Benbow and Bridg- } \\
\text { water (1993) }\end{array}$ & 25.4 & $2,5.1,9.3$ & 0.540 & 0.0254 & 0.440 & 0.025 & 0.008 & 0.76 \\
\hline Barnes et al. (2006) & 25 & 8 & 0.122 & 0 & 1 & 0.036 & 0.0018 & 0.7 \\
\hline Castro et al. (2010) & 12 & $0.5,1,2$ & 0.2 & 0 & 1 & - & - & - \\
\hline
\end{tabular}

quantity $V_{\mathrm{ex}} / D$, cf. the shear rate in the flow of a Newtonian fluid in a pipe $\left(8 V_{\text {ex }} / D\right)$. While the Benbow-Bridgwater model scales with $V_{\text {ex }}$, the missing ${ }_{205} 1 / D$ dependence would normally absorb into the fitted parameters $\sigma_{0}$ and $\alpha$ neatly, as long as the 'size' of the extruder remained constant for all experiments. This reflects the fact that the parameters are pseudo-properties linked to both the experimental conditions and the material, rather than a true measurement of the material behaviour. The apparent shear rate was used to perform scaleup modelling of PTFE paste extrusion by Ardakani et al. (2013), though the data were not considered in the context of the Benbow-Bridgwater model.

The variation in $\tau_{\mathrm{W}}$ is more difficult to reconcile as the factors likely to affect the wall slip, the slipping material and the wall itself, were constant throughout all of the experiments. A possibility is that the wall slip behaviour of soap is pressure-dependent, in that the increased extrusion pressure in the smaller extruders would act to increase $\tau_{\mathrm{W}}$ due to enhanced material-wall contact. Pressure-dependent slip is somewhat supported by experiments reported separately (Bryan et al., 2017), though the magnitude of the effect here is larger. This type of slip is not often suggested for fluid-like materials but it is possible that soap behaves more like a solid in this context, which typically show normal stress-dependent friction. Also possible is that some difference in the surface- 
material interaction affects the $\tau_{\mathrm{W}}$ values in the three extruders. It was not possible to study this further in the context of the present work, though Bryan et al. (2017) does present data from extruders constructed of different materials and with different surface finishes, finding that this can affect $\tau_{\mathrm{W}}$ measurements by a similar magnitude.

While table 2 shows that there is substantial variation in Benbow-Bridgwater parameters reported in the literature for materials which are all classed as soap, the current findings indicate that even greater care must be taken when comparing values originating from different geometries. It is also worth repeating that the flexibility afforded by the fitting process allows incorrect interpretation of the data; in this instance a very specifically crafted set of experiments was required to reveal the discrepancy with extruder scale. The current findings are of direct consequence to scale-up operations in industry, where large production extruders may perform differently to laboratory scale devices despite the material being the same.

The data for $\sigma_{\mathrm{Y}}$ were able to be represented by applying the Basterfield et al. (2005) model, equation 2a, as shown in figure 5. Some improvement in the agreement between the three sets of data is expected, as the Basterfield 240 et al. model uses the characteristic shear rate $V_{\mathrm{ex}} / D$ as its scaling quantity for $P_{1}$, rather than $V_{\text {ex }}$ alone.

The fit to the data is satisfactory, and the Herschel-Bulkley parameters calculated were $\sigma_{\mathrm{Y}, \mathrm{HB}}=0.57 \mathrm{MPa}, k_{\mathrm{HB}}=0.28 \mathrm{MPa} \mathrm{s}^{0.44}$ and $h=0.44$. The effective fourth fitting parameter, $\theta$, was found not to influence substantially the rheological parameters between values of 40 and $90^{\circ}$ in agreement with observations in Basterfield et al. (2005). Without evidence to support a particular value of $\theta, 45^{\circ}$ was chosen as a neutral value to be validated later through flow visualisation.

The yield stress of $0.57 \mathrm{MPa}$ is large for a material being treated as a fluid. 250 The magnitude, however, is unsurprising as the soap is effectively a solid block within the extruder. The large value does cast doubt on the applicability of the model when most Herschel-Bulkley materials have yield stresses on the order 


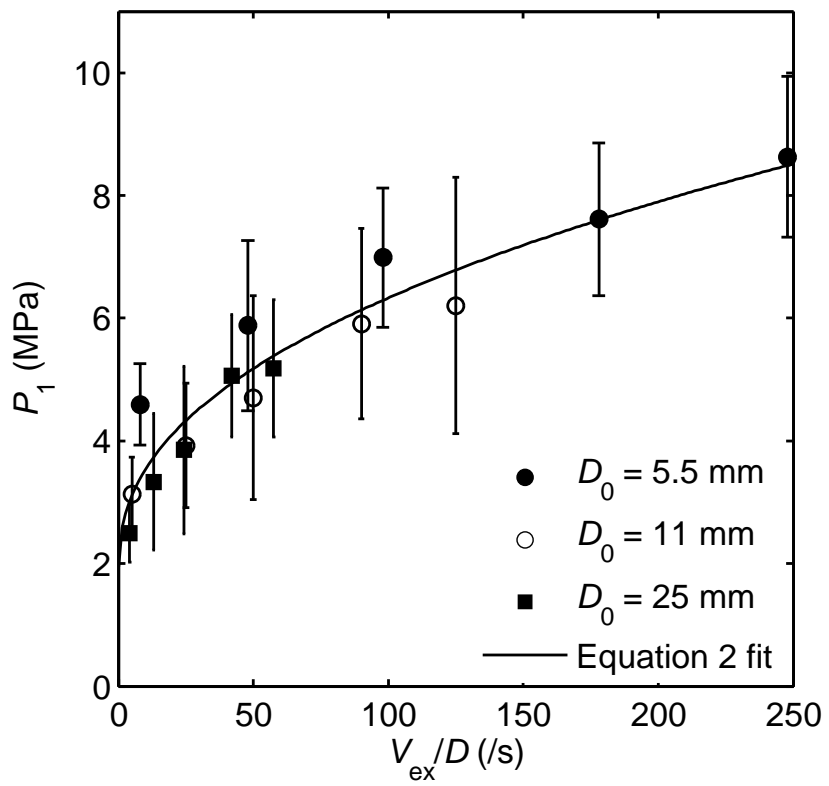

Figure 5: $P_{1}$ as a function of characteristic shear rate $V_{\mathrm{ex}} / D$. Solid locus shows the Basterfield et al. model fit to the data assuming a $\theta=45^{\circ}$ converging region. Error bars represent the $90 \%$ confidence interval for the Bagley-type plot intercepts.

of a few pascals.

It is also notable that the fitted value of $\sigma_{\mathrm{Y}, \mathrm{HB}}$ is smaller than the BenbowBridgwater parameter $\sigma_{0}$ for all three extruders tested. This is further confirmation that the deformation behaviour is more complex than the pseudo-plastic model used by Benbow and Bridgwater, as the Basterfield et al. model places more weight on rate-dependent viscous effects in generating the resistance to flow, rather than contributions from the yield stress.

A further test enabled by the Herschel-Bulkley parameters is calculation of the expected wall shear stresses in each die assuming no slip at the wall; these can be compared to the experimental values in figure 4(b). These calculations, using an expression for the pressure gradient in a flowing Herschel-Bulkley fluid found in Stainsby (1998), provide $\tau_{\mathrm{W}}$ values an order of magnitude greater than those seen experimentally, in the range 0.7-8 MPa as opposed to 0.08-0.4 MPa. This confirms that the soap slips at the walls of the extruder, if it is assumed 
that the parameters used are representative of the material.

\subsection{Numerical simulations}

When applied to numerical simulations of the same flows the Basterfield et al. seen experimentally. The wall interaction was specified by equation 4 (shown in figure 4(b)), which does match the observed experimental behaviour. While the magnitude of the extrusion pressures were comparable, there was found to be minimal effect of extruder scale in the simulated results. This suggests that the in the entry zone.

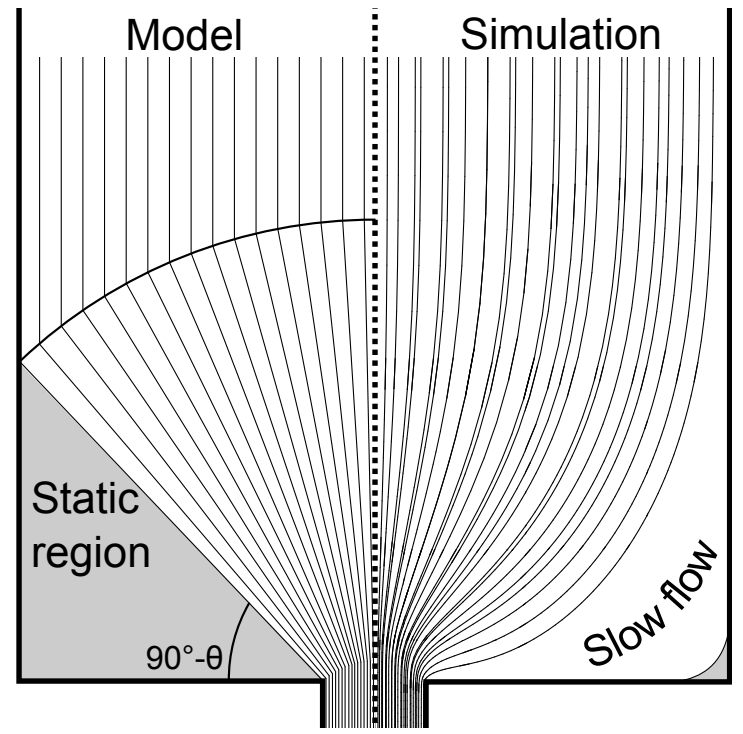

Figure 6: Comparison of the Basterfield et al. velocity field (left) with the simulated velocity field (right) for a typical cylindrical extrusion. Grey areas are the regions of static material either assumed or calculated in each case, using a value of $\theta=45^{\circ}$ on the left. 
Adjusting the Herschel-Bulkley parameters to lower the yield stress relative to the viscosity coefficient, $k_{\mathrm{HB}}$, was found to increase the variation in $P_{\mathrm{ex}}$ with extruder scale, shown in figure 7 . This arises from a reduction in the shearthinning character of the fluid, amplifying the effect of the increased shear rate in smaller extruders $\left(V_{\mathrm{ex}} / D\right.$ for constant $\left.V_{\mathrm{ex}}\right)$, which generates larger extrusion pressures. While this does improve agreement with the experimental data, it does so by effectively treating the soap as a power law fluid with minimal yielding character, despite its solidity when not under stress.

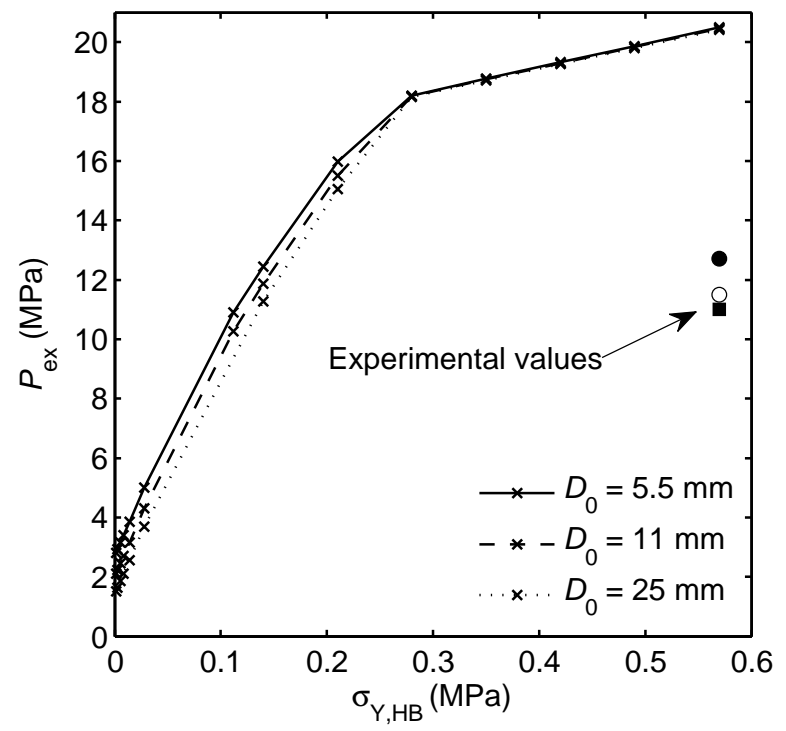

Figure 7: Effect of adjusting the Herschel-Bulkley yield stress for constant $k_{\mathrm{HB}}=0.28 \mathrm{MPa}$ $\mathrm{s}^{0.44}$ and $h=0.44$, for extrusion using three barrel diameters at $L / D=12$ and $V_{\mathrm{ex}}=250$ $\mathrm{mm} / \mathrm{s}$. The data points are experimental values for these conditions, where $D_{0}=\bullet-5.5 \mathrm{~mm}$, $\circ-11 \mathrm{~mm}, \mathbf{\square}-25 \mathrm{~mm}$.

Similarly, modifying the simulated flow boundary condition towards one of no-slip also caused an increase in the effect of extruder scale, shown in figure 8. This arises because a no-slip condition causes shear of material in both the barrel and die (rather than plug flow), acting to increase energy dissipation and so the extrusion pressure. As the shear rate is larger in smaller extruders (the soap velocity being equal), this increases the extrusion pressure in the smaller geometries, matching the experimental trend. This is, however, a false result as 
a no-slip condition is not representative of paste flows. Moreover, the analytical wall shear stress assuming no slip was already calculated and found to be much larger than that determined experimentally, implying a slip condition in the real system. Notable also is the sensitivity of the extrusion pressure to the degree of wall slip over a very small range of slip velocities, indicating that accurate material properties alone are not sufficient to simulate extrusion, but only in combination with a good model of the boundary behaviour.

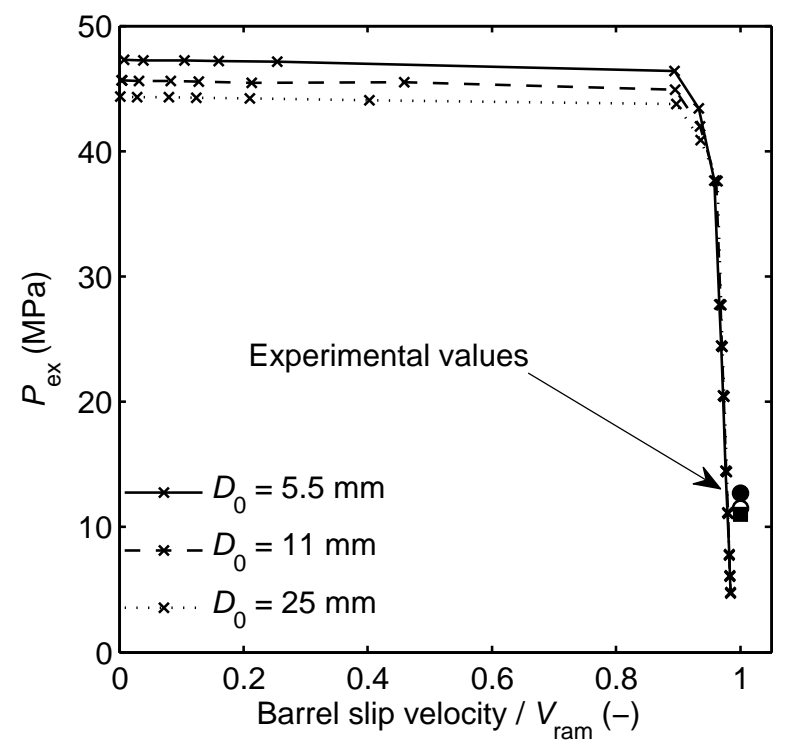

Figure 8: Effect of the slip velocity on the simulated extrusion pressure for constant material properties, for extrusion using three barrel diameters at $L / D=12$ and $V_{\text {ex }}=250 \mathrm{~mm} / \mathrm{s}$. The slip velocity was adjusted by changing the slip parameter $\beta$ through four orders of magnitude. The data points are experimental values for these conditions, where $D_{0}=\bullet-5.5 \mathrm{~mm}$, ० -11 $\mathrm{mm}, \mathbf{\square}-25 \mathrm{~mm}$.

Extensive adjustment of the five available parameters (three material and two wall interaction properties) was able to bring simulation and experimental data into closer alignment, including the variation of $P_{\text {ex }}$ with scale. However, the insight to be gleaned from this parameter fitting exercise was limited at best, as it is likely there are multiple sets of parameters which satisfy the data. In reality this is proof that the choice of wall and material models was inappropriate for soap extrusion from the outset. 


\subsection{Flow visualisation}

To gain further information on the flow behaviour, and in doing so guide the choice of models used to represent it, several types of flow visualisation were carried out. These results can also be compared to both the theoretical flow pattern implied by the Basterfield et al. model and the simulated flow patterns generated previously.

Contrasting paste extrusions using the full cylindrical extruder were first conducted owing to their simplicity. Black, graphite-stained soap was extruded in sequence before normal, uncoloured soap and the patterns remaining in each billet after cross-sectioning were imaged, shown in figure 9 . These images were taken from separate, interrupted extrusions of identical bi-colour soap billets after different ram displacements, and give an indication how the initially flat interface between the black and white soap deforms as it nears the die.

The images show an almost complete lack of interface deformation until the black-stained soap has extruded through the die, suggesting that the flow field remains uniform (in plug flow) except in a very narrow layer near the die itself. This behaviour was also observed when extruding white soap followed by blackstained soap, confirming that the effect is not a result of the testing method. Such a result is unusual when compared to similar experiments in the literature, where the interface is typically seen to deform towards the orifice well upstream of the die, on the order of one barrel diameter from the entrance (as in Bryan et al. (2015)).

Also notable is the small extent of the static regions at the barrel-die corners after sufficient unstained soap has extruded. Static regions at the corners of the extruder have been observed in ram extrusion of numerous materials such as PTFE resins, cement and in soap itself (Castro et al., 2010), but there is very little consistency over the extent of these regions between different materials. Bryan et al. (2015) observed smaller static regions in micro-crystalline cellulose extrusion than other sources in the literature (for different materials), but the present static regions in soap extrusion are smaller still, on the order of $1 \mathrm{~mm}$ characteristic size in a $25 \mathrm{~mm}$ diameter barrel (cf. $3 \mathrm{~mm}$ in a $25 \mathrm{~mm}$ barrel for 


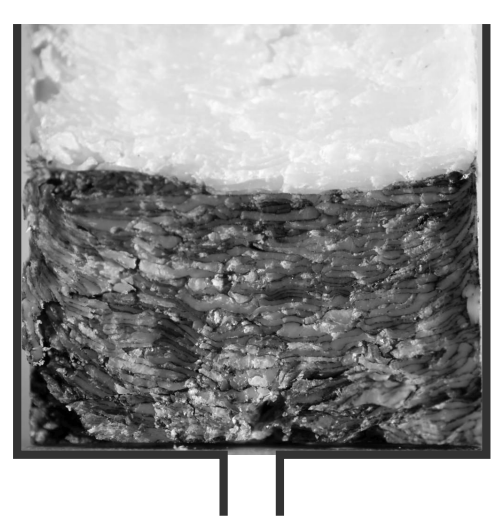

(a) $20 \mathrm{~mm}$

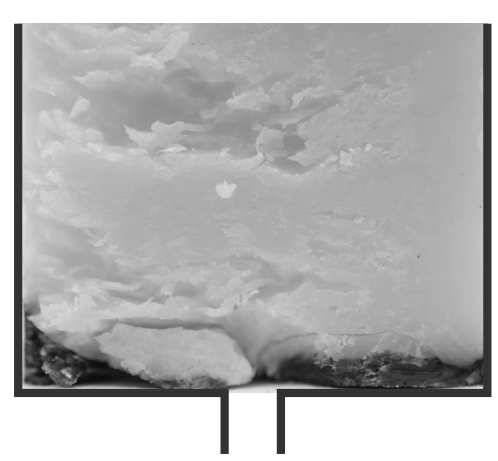

(c) $35 \mathrm{~mm}$

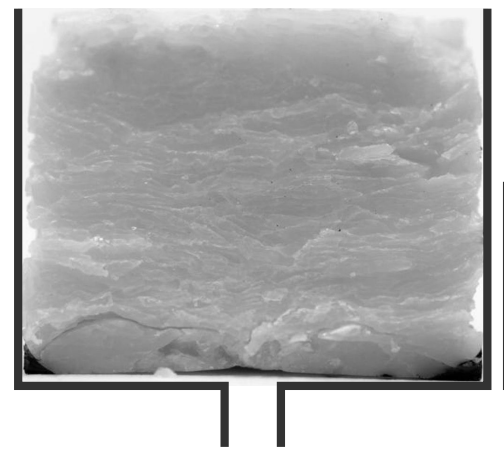

(e) $50 \mathrm{~mm}$

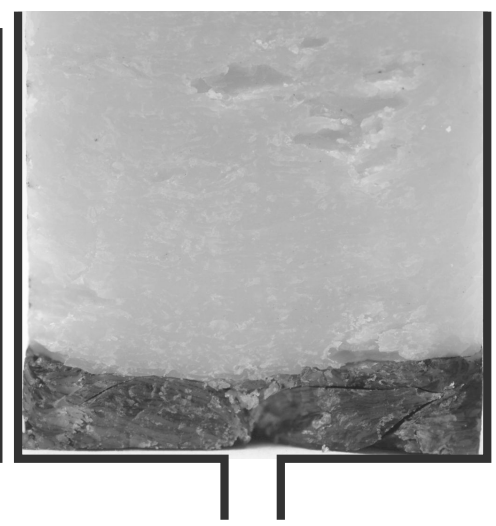

(b) $30 \mathrm{~mm}$

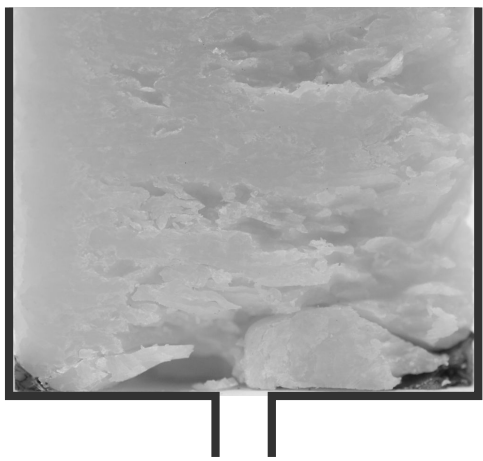

(d) $40 \mathrm{~mm}$

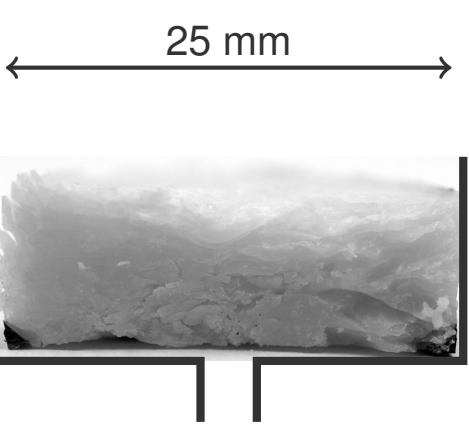

(f) $60 \mathrm{~mm}$

Figure 9: Images of the cross-sections of extruded billets of soap consisting of $50 \%$ blackstained material followed by uncoloured soap. Extrusion direction is from top to bottom. Ram displacement is marked below each image. Barrel diameter $25 \mathrm{~mm}$, die diameter $3 \mathrm{~mm}$, initial billet height $70 \mathrm{~mm}$, and ram velocity $1 \mathrm{~mm} / \mathrm{s}$. 
micro-crystalline cellulose).

These observations were confirmed and expanded upon using the windowed hemicylindrical extruder. The flow videos were processed to provide a visual record of the particle tracks akin to streak photographs generated by a long film exposure of the flow. Examples of these are shown in figure 10 for both square-entry and conical-entry extruder configurations. These images can be compared to the simulated and model velocity fields shown in figure 6 .

For the square-entry case, as in the contrasting paste extrusion images, it is observed that the flow remains largely uniform across the barrel until approximately $5 \mathrm{~mm}$ upstream of the die, and that there is negligible static material at the corners of the extruder (revealed by a lack of stationary tracer spheres there). This implies that the flow is effectively horizontal along the die face, and by extension the soap must slip against this wall.

A further implication of this is that the effective value of $\theta$ (the conical halfangle in the Basterfield et al. model) is $90^{\circ}$, rather than $45^{\circ}$ as used in fitting. However, at $\theta=90^{\circ}$ the conical flow area has zero penetration into the barrel (referring to figure 6), and a value of $\theta=70^{\circ}$ more closely replicates the pattern of particle tracks (albeit without capturing the flow along the die face or in the corners of the extruder).

In contrast, the conical-entry extruder effectively imposes the same flow field assumed by Basterfield et al. (with $\theta=30^{\circ}$ ). This is especially true as the soap slips readily against the extruder walls, mimicking the frictionless conical walls used in the derivation. The path photograph demonstrates the marked difference between the flow in the two extruders and invalidates the assumption that the static regions would form such a conical flow pattern, at least in the case of soap flow. The conical geometry also caused an increase in the extrusion pressure of order $30 \%$ compared to the square-entry case. This increase can be attributed to a larger zone of shear and extension affecting the same degree of change in cross-sectional area of the material, causing more energy to be dissipated in the extrusion process.

It is noteworthy that in both images path-lines cross on the approach to the 


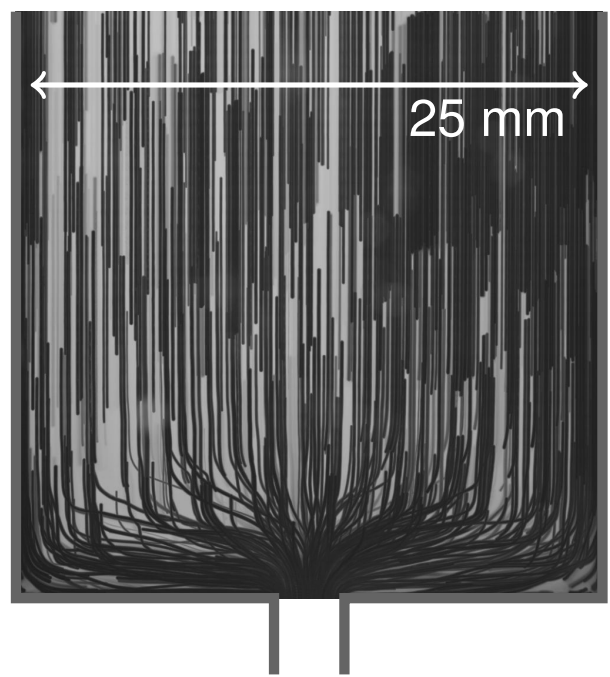

(a) Square-entry

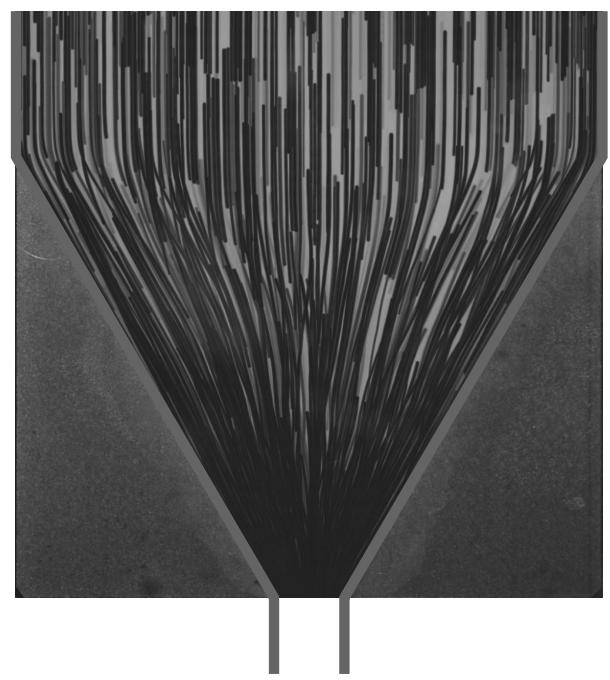

(b) Conical-entry

Figure 10: Path photographs of extruding soap in the windowed hemicylindrical extruder in both a square-entry and conical-entry configuration. Barrel diameter $25 \mathrm{~mm}$, die diameter 3 $\mathrm{mm}$, ram velocity $0.1 \mathrm{~mm} / \mathrm{s}$, conical half angle $30^{\circ}$. 
die. This is evidence that the material is not homogeneous, a key assumption of any fluid model, as homogeneity would ensure consistent particle trajectories throughout the extrusion. This variability in flow pattern is likely due to the granular nature of the soap, which is loaded into the barrel as plate-like pellets. A similar variability in the flow pattern was noted in soap extrusion by Barnes et al. (2006). Despite a thorough pre-compaction of the billet prior to extrusion, some of the granular structure survives the loading process and confers anisotropy to the material, causing the flow to fluctuate slightly as the extrusion proceeds. Similar behaviour was observed in separate experiments during extrusion of micro-crystalline cellulose, which is also granular, but not with a more typical viscoplastic fluid, a carbopol gel (MCC image shown as supplementary material, Carbopol data not reported). A potential method to overcome the heterogeneity in soap would be to use an alternative extruder loading technique, pouring molten soap into the barrel before allowing it to solidify into a billet.

A hypothesis for the particular shape of the flow field in the square-entry case also stems from the lamellar nature of the soap granules, which were typically found to align horizontally in the barrel after loading. This configuration will ensure that deformation in the horizontal plane (plates sliding past each other) is easier than in the vertical direction (requiring the granules themselves to deform or break). On initiation of the extrusion, the deformation field requiring the least energy input will start first (primarily horizontal translation near the die). This material is replaced by soap moving downstream in plug flow, whereupon the cycle repeats. This mechanism is enabled by the low friction between the walls of the extruder and the soap as it enables the flow along the die face, perpendicular to the dominant axial direction of flow.

Quantitative analysis of the visualisation data provides the time-averaged 400 velocity at each point in the flow field. Defining a cylindrical coordinate system $(r, \phi, z)$ in the vertical barrel with origin at the die entrance and assuming axisymmetry with no swirl ( $\phi$ velocity zero), the velocity at any point can be represented as two components $V_{r}$ and $V_{z}$ (radial and axial velocity) along 
diameters of the barrel (at height $z$ above the die). The components from the square-entry flow visualisation case are compared to both the simulated and model velocity fields in figure 11. For the calculation of the Basterfield et al. model velocity field, a half-angle $\theta$ of $70^{\circ}$ was used as discussed above.

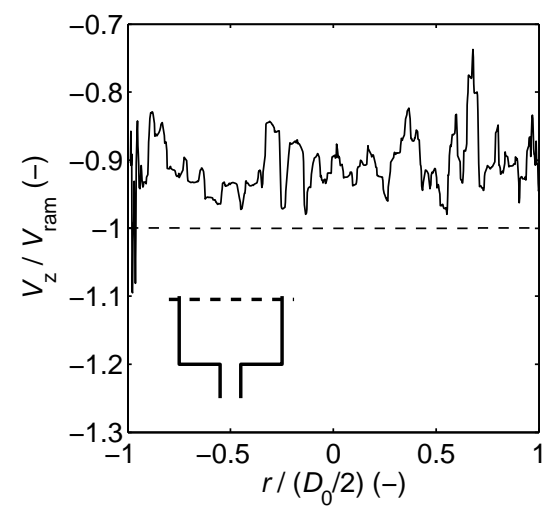

(a) Axial velocity, $z=20 \mathrm{~mm}$

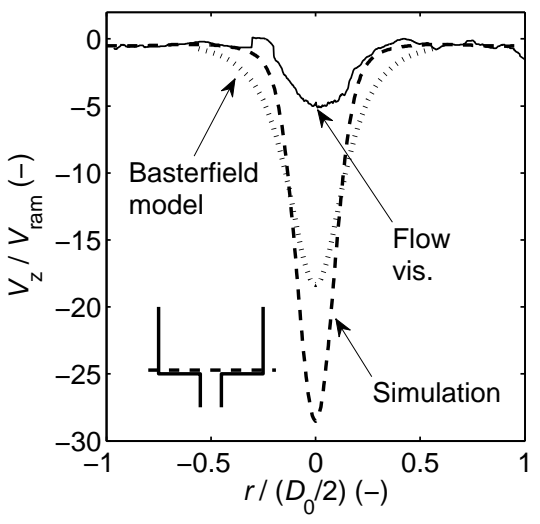

(c) Axial velocity, $z=2 \mathrm{~mm}$

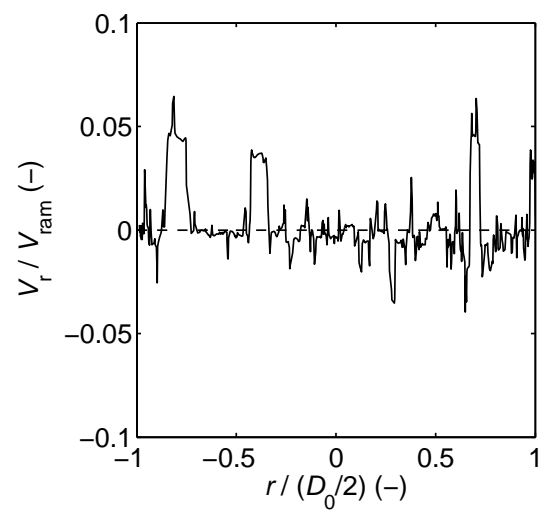

(b) Radial velocity, $z=20 \mathrm{~mm}$

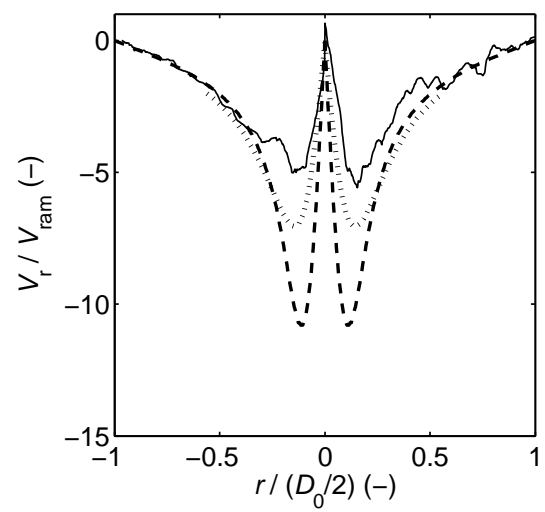

(d) Radial velocity, $z=2 \mathrm{~mm}$

Figure 11: Axial and radial velocity profiles along horizontal cross-sections (a), (b) 20 and (c), (d) $2 \mathrm{~mm}$ above the die (shown in inset diagrams), $V_{\mathrm{ram}}=0.1 \mathrm{~mm} / \mathrm{s}$. Solid lines are flow visualisation results from the square-entry windowed hemicylindrical extruder, dashed lines are simulation profiles and dotted lines are the Basterfield et al. velocity profile (with a half-angle $\theta=70^{\circ}$ ).

The velocity profiles furthest upstream of the die, describing pure axial plug flow, serve as a form of validation of the visualisation system as the velocity at this location is expected to be close or equal to that of the ram. The 
velocity recorded here is on the order of 85 to $95 \%$ of the ram velocity, suggesting that the glass window and the hemicylindrical geometry act somewhat to slow the flow, but likely not enough to affect the flow pattern substantially. Manual confirmation of the tracer sphere velocities was also carried out to test the automated algorithm; these calculated velocities typically agreed with the time-averaged values to an acceptable level, with some error attributed to the previously noted variation in the flow field itself.

The sequence of plots describes quantitatively the same conclusions which were derived from the path photographs, revealing the upstream axial plug flow changing over to fast inward radial flow near the die. In a series of experiments at different ram velocities, there was found to be no substantial change to the flow field in soap with speed, though some variation was noted in both microcrystalline cellulose and a carbopol gel (data not reported). The performance of the visualisation system for carbopol gel was poor, however, as there was insufficient wall slip between the glass and gel to be confident that the flow field was not substantially altered from the fully cylindrical case.

Comparing the data to the simulated and model profiles, it is clear that there is good agreement in the plug flow region far upstream of the die. Nearer the die the agreement is poor, and in particular the experimental centreline 430 axial velocity is substantially lower than both the simulation and model. Close inspection of videos of the flow confirmed that this low velocity is real (and not an artefact of the automated algorithm). A hypothesis for the apparent slow flow in this area is that the soap is less able to slip against the glass near the entrance to the die, due to radial flow towards the window acting to increase the normal stress in this location. Still, the data do give some insight into the form of the velocity field even if the precise magnitudes are hard to verify.

There are evident differences between the simulated flow and the model close to the die, despite both being based on the analysis of a Herschel-Bulkley fluid, the latter being predominately axial flow while the simulation includes 440 substantial radial flow. This is due to the wall slip condition applied in the numerical case, allowing the material to approach the orifice along the die wall, 
while the model itself assumes that all material contacting the die is static.

Similar comparisons can be made for the conical-entry extruder, using the same geometry as the experimental hemicylindrical extruder to specify the simulation and model profiles, shown in figure 12 .

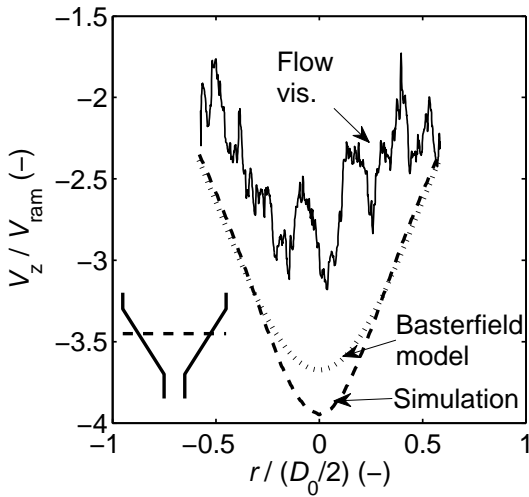

(a) Axial velocity, $z=10 \mathrm{~mm}$

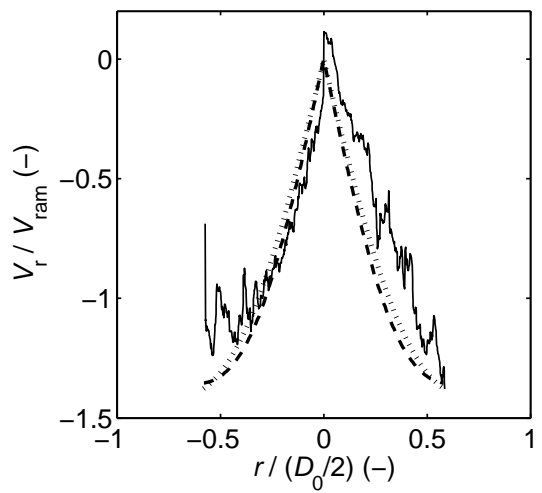

(b) Radial velocity, $z=10 \mathrm{~mm}$

Figure 12: (a) Axial and (b) radial velocity profiles along a horizontal cross-section $10 \mathrm{~mm}$ above the die entrance (shown in inset diagram) in the conical-entry extruder $\left(V_{\mathrm{ram}}=0.1\right.$ $\mathrm{mm} / \mathrm{s}$ ). Solid lines are flow visualisation results from the conical-entry windowed hemicylindrical extruder, dashed lines are simulated profiles and dotted lines are the Basterfield et al. velocity profile (assuming an angle $\theta=30^{\circ}$ ).

These show greater agreement between the three profiles, which is due to the converging velocity field being dictated by the geometry rather than being allowed to develop naturally from the material and wall interaction properties. There is hence better justification for using the Basterfield et al. model for conical-entry geometries, and that this will be valid for a wider range of materials than in the square-entry case.

\section{Conclusions}

Solid granular soap has been shown to be an effective and reliable material for soft solid extrusion research, in agreement with other instances of its use in the literature.

The work presented, combining traditional extrusion characterisation, flow visualisation and simulations, highlights that while extrusion models may be 
able to fit any particular set of extrusion pressure data, this does not mean they adequately capture all potential dependencies which determine the flow. The Benbow-Bridgwater model was found to be lacking some dependence on absolute scale of the extruder, rather than a ratio of scales. This lack is normally not an issue as most research uses only one extrusion device. The Basterfield et al. model uses different assumptions about the flow, and was found to be able to accommodate the observed discrepancies successfully, but the application of the model was then found to be an incorrect choice in comparison to both flow visualisation and simulations. Similarly, the numerical simulations of the flow were initially unable to match the experimental data, suggesting that the choice of material and slip models was inappropriate. That said, with sufficient time spent modifying parameters it was found that simulations could be brought 470 into close agreement with experimental extrusion pressures, but without good agreement with the velocity field in the extruder or any increase in confidence as to the validity of the models used.

It is clear great care must be taken when using a particular model of extrusion, to ensure that there is no reliance on falsely convincing agreement between experiment and model. This is especially true when comparing information gathered from different materials and extruders, which could appear similar in the context of a model while disguising vastly different flow behaviour and material rheology. Increasing the amount of instrumented data collection for extruders is one method to avoid false positives, for example by incorporating pressure transducers or mass flow-rate sensors into the equipment to allow better validation of model predictions.

\section{Acknowledgements}

The funding for this project was kindly provided by Ceratizit $\mathrm{GmbH}$ and Sandvik AB.

\section{Nomenclature}

\section{Roman}


A Basterfield model conical parameter

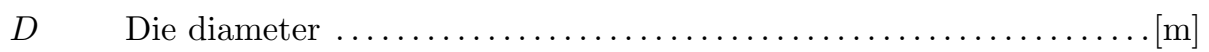

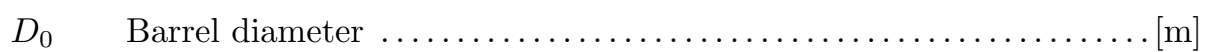

${ }_{490} \quad h \quad$ Herschel-Bulkley shear rate exponent $\ldots \ldots \ldots \ldots \ldots \ldots \ldots \ldots[-]$

$k_{\mathrm{HB}} \quad$ Herschel-Bulkley viscosity coefficient $\ldots \ldots \ldots \ldots \ldots \ldots \ldots \ldots \ldots \ldots$ Pa s $\left.{ }^{h}\right]$

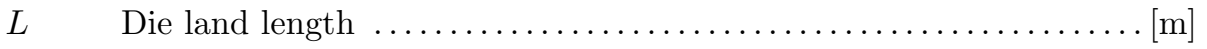

$m \quad$ Benbow-Bridgwater exponent for velocity-dependent yield stress ... [-]

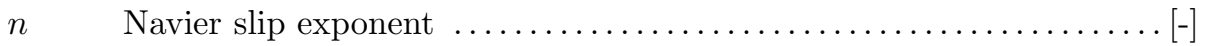

$P_{\text {ex }} \quad$ Extrusion pressure $\ldots \ldots \ldots \ldots \ldots \ldots \ldots \ldots \ldots \ldots \ldots \ldots \ldots \ldots \ldots \ldots \ldots \ldots \ldots \ldots$

$P_{1} \quad$ Extrusion pressure component, deformation $\ldots \ldots \ldots \ldots \ldots \ldots \ldots[\mathrm{Pa}]$

$P_{2} \quad$ Extrusion pressure component, die wall friction $\ldots \ldots \ldots \ldots \ldots \ldots[\mathrm{Pa}]$

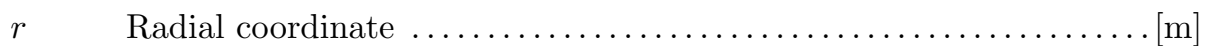

$V_{\mathrm{ex}} \quad$ Extrudate velocity $\ldots \ldots \ldots \ldots \ldots \ldots \ldots \ldots \ldots \ldots \ldots \ldots \ldots \ldots \ldots \ldots \ldots \ldots$

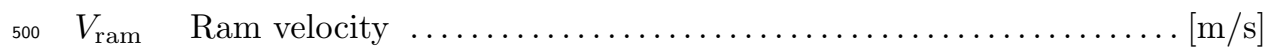

$V_{\mathrm{r}} \quad$ Radial velocity $\ldots \ldots \ldots \ldots \ldots \ldots \ldots \ldots \ldots \ldots \ldots \ldots \ldots \ldots \ldots \ldots \ldots \ldots \ldots \ldots$

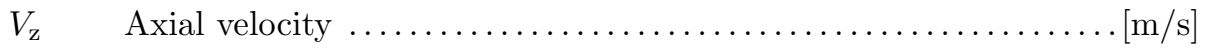

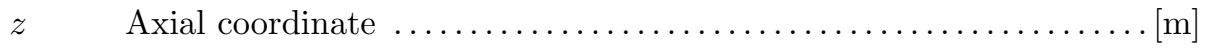

\section{Greek}

${ }_{505} \alpha \quad$ Benbow-Bridgwater velocity scale for yield stress $\ldots \ldots \ldots\left[\mathrm{Pa} /(\mathrm{m} / \mathrm{s})^{m}\right]$

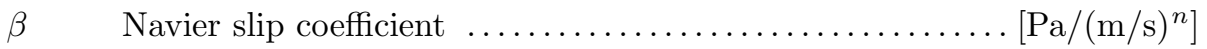

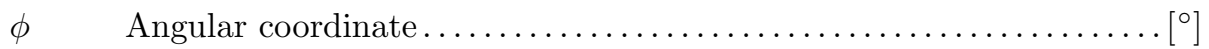

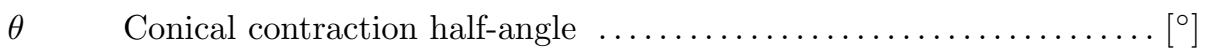




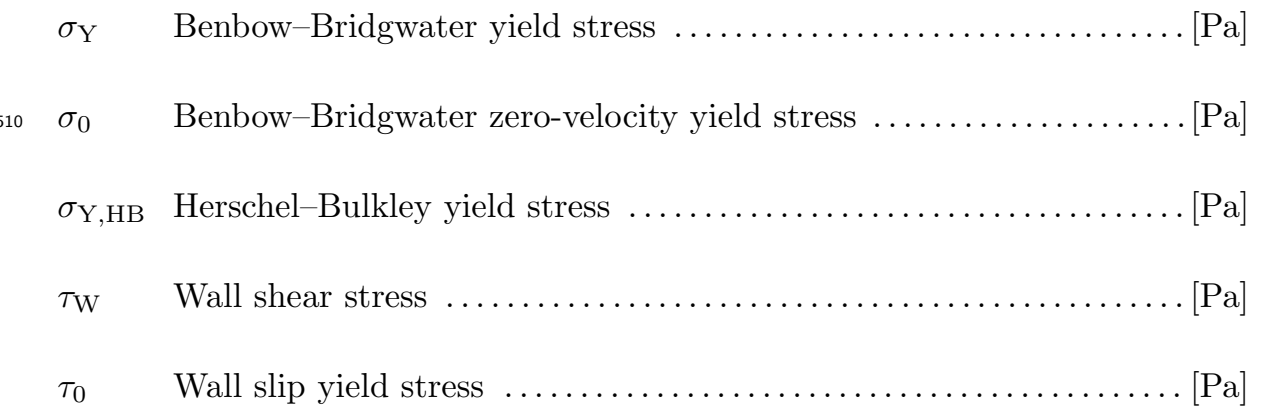

\section{Supplementary material}

Micro-crystalline cellulose (MCC) is an inert plant-derived biopolymer used in the pharmaceutical industry as an excipient. It has been extensively used as an extrusion material in the literature owing to the manufacture of pharmaceutical products through extrusion-spheronisation (Dukic-Ott et al., 2009).

A micro-crystalline cellulose paste was mixed from the dry powder (45 wt\%) and distilled water (55 wt\%) using the protocol described by Zhang et al. (2011). This was extruded using the same barrel and die sets used for soap, at the same extrusion velocities. Extrusion pressure results for one velocity are shown in figure 13.

The same trend in extrusion pressure with scale can be seen for MCC as with soap, though the magnitude of the variation is smaller. It is clear that MCC is a softer material than soap, in which the range of $P_{\text {ex }}$ values was 5-22 MPa. Extrusion data for the full range of velocities were processed as described previously to determine the Benbow-Bridgwater parameters $\sigma_{\mathrm{Y}}$ and $\tau_{\mathrm{W}}$, shown in figure 14 .

MCC behaves differently to soap by this measure, as the measured yield stress is not a function of extrusion velocity. This is in agreement with the findings of Zhang et al. (2011) who reported a $\sigma_{\mathrm{Y}}$ value of $0.28 \mathrm{MPa}$ using a $25 \mathrm{~mm}$ diameter extrusion barrel (with 1,2 and $3 \mathrm{~mm}$ diameter single-holed dies). The current results do show, however, variation of $\sigma_{\mathrm{Y}}$ with extruder scale consistent with the data for soap, in that the yield stress appears to increase in smaller extruders. 


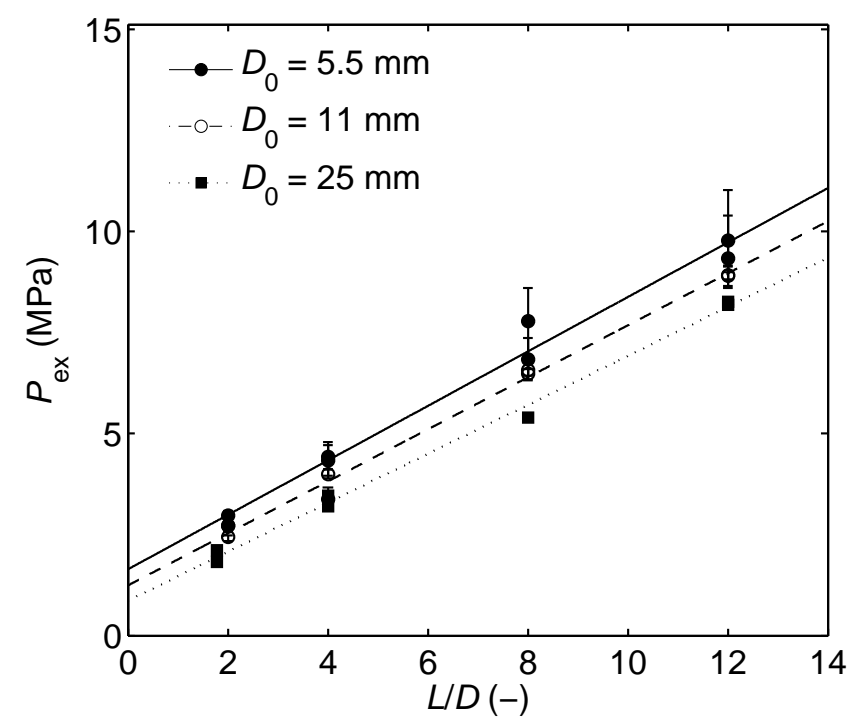

Figure 13: Bagley-type plots of MCC extrusion in three geometrically identical, different-sized extruders at $V_{\mathrm{ex}}=100 \mathrm{~mm} / \mathrm{s}$. Straight lines are least squares best fits to the data, and error bars represent the 10th and 90th percentiles of extrusion pressure as sampled.

A constant value of yield stress with extrusion rate can be attributed to a material which acts pseudo-plastically, i.e. one which has a negligible viscous contribution to its rheology. In contrast to soap, the MCC data do not conform to the Basterfield et al. (2005) extrusion model as they do not scale with apparent shear rate $\left(V_{\mathrm{ex}} / D\right)$. It is then intriguing why the Benbow-Bridgwater $\sigma_{\mathrm{Y}}$ term varies with scale in this case; in soap this was attributed to differences in shear rate in each extruder not accounted for by the model.

Also in contrast to soap, the value of $\tau_{\mathrm{W}}$ in MCC does not change with extruder scale. While the trend in the soap data was attributed to pressuredependent slip, in the much wetter MCC mixture such behaviour is not expected as the liquid would lubricate the slip more effectively.

MCC was also tested using the hemicylindrical flow visualisation tool. For completeness, figure 15 shows a path photograph of MCC extruding under the same conditions as the soap in figure 10. Notable are the larger static (or slow flowing) regions at the barrel-die corners in MCC, and the generally larger zone of deformation (curved particle tracks), extending approximately $0.5 D_{0}$ from 


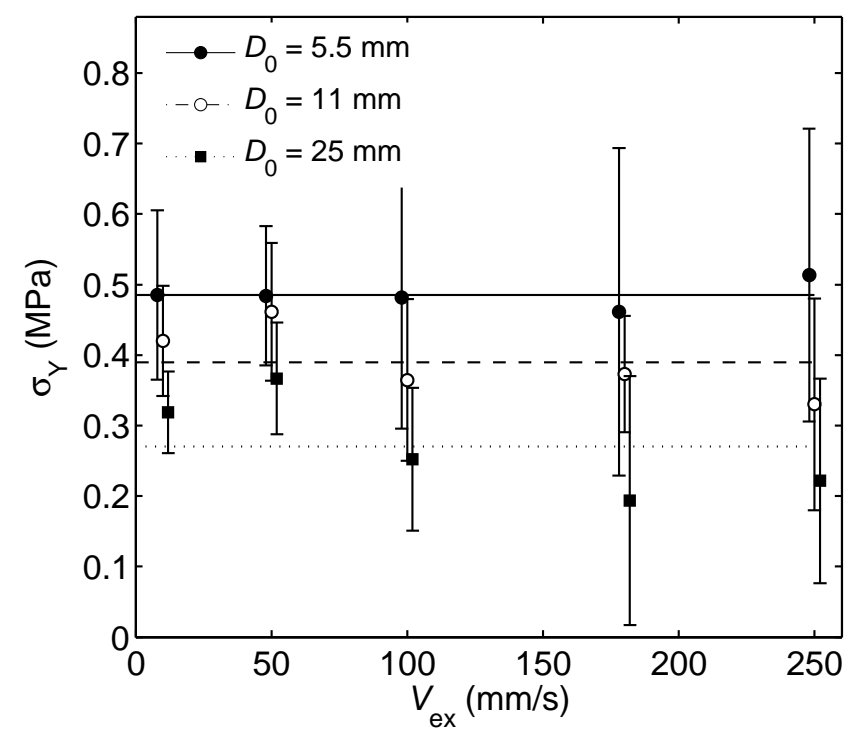

(a)

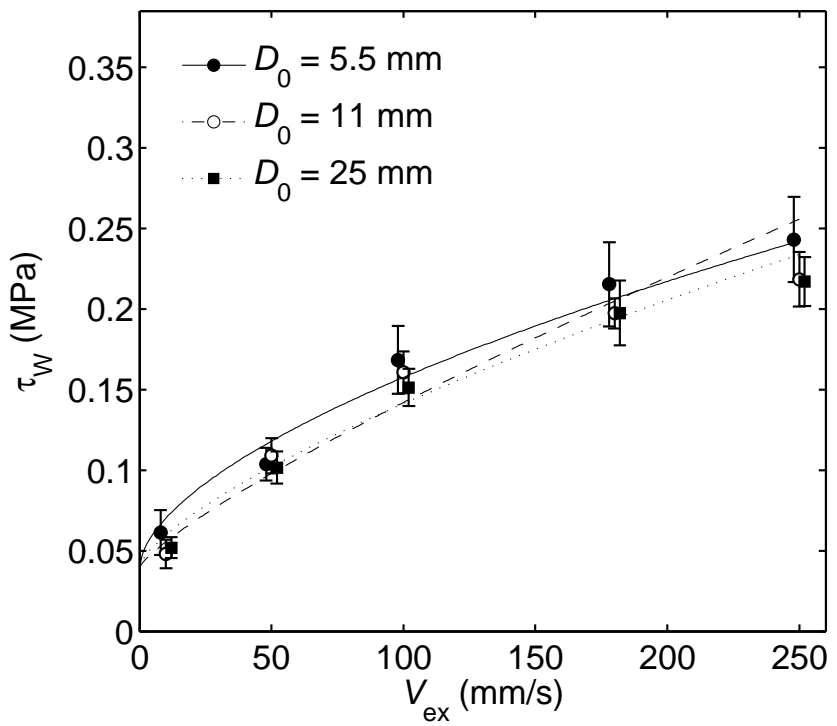

(b)

Figure 14: Benbow-Bridgwater parameters for MCC, (a) yield stress and (b) wall shear stress, in three sizes of extruder. Lines in (a) are the arithmetic average through the data for each barrel. Lines in (b) are power law fits assuming an intercept of $\tau_{0}=0.04 \mathrm{MPa}$. Error bars represent $90 \%$ confidence interval for the Bagley-type plot intercepts and slopes. Points are offset along the velocity axis for clarity. 
the die as opposed to $0.2 D_{0}$ in soap. Also visible are crossed particle tracks, which were observed in soap, indicative of non-homogeneous behaviour of the material.

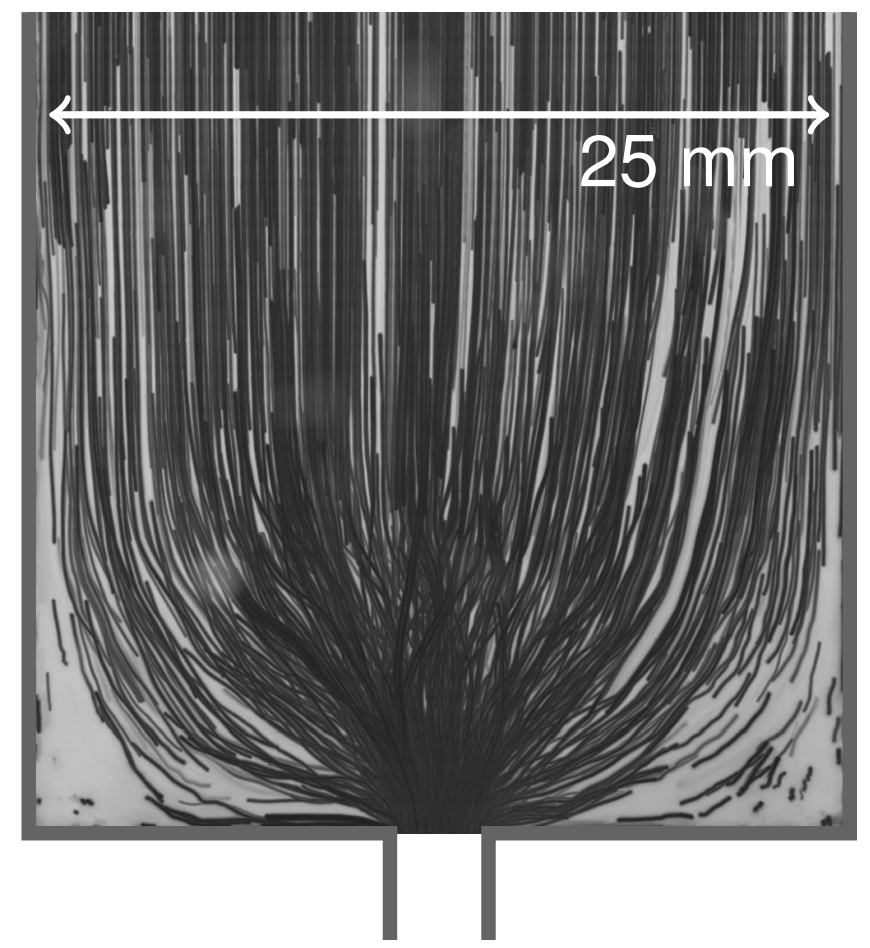

Figure 15: Path photograph of extruding MCC in the windowed hemicylindrical extruder in the square-entry configuration. Barrel diameter $25 \mathrm{~mm}$, die diameter $3 \mathrm{~mm}$, ram velocity 0.1 $\mathrm{mm} / \mathrm{s}$.

\section{Bibliography}

Abdali, S. S., Mitsoulis, E., Markatos, N. C., 1992. Entry and exit flows of Bingham fluids. Journal of Rheology 36 (2), 389-407.

URL http://scitation.aip.org/content/sor/journal/jor2/36/2/10.

Althaus, T. O., Windhab, E. J., 2011. Extrusion of highly unsaturated wet powders: Stress fields in extruder barrels. Powder Technology 211 (1), 10-18. 
URL

http://www.sciencedirect.com/science/article/pii/ S0032591011001057

Amarasinghe, S., Wilson, D. I., 1998. Interpretation of paste extrusion data. Chemical Engineering Research and Design 76 (1), 1-6.

Ardakani, H. A., Mitsoulis, E., Hatzikiriakos, S. G., 2013. A simple improved mathematical model for polytetrafluoroethylene (PTFE) paste extrusion. Chemical Engineering Science 89, 216-222.

Ariawan, A. B., Ebnesajjad, S., Hatzikiriakos, S. G., 2002. Paste extrusion of polytetrafluoroethylene (PTFE) fine powder resins. The Canadian Journal of Chemical Engineering 80 (6), 1153-1165.

Barel, A. O., Paye, M., Maibach, H. I., 2005. Handbook of Cosmetic Science and Technology Second Edition. CRC Press. URL https://books.google.co.uk/books?id=sQzNBQAAQBJ

Barnes, E. C., Wilson, D. I., Johns, M. L., 2006. Velocity profiling inside a ram extruder using magnetic resonance (MR) techniques. Chemical Engineering Science 61 (5), 1357-1367.

URL http://linkinghub.elsevier.com/retrieve/pii/ S0009250905007062

Barnes, H. A., 1995. A review of the slip (wall depletion) of polymer solutions, emulsions and particle suspensions in viscometers: its cause, character, and cure. Journal of Non-Newtonian Fluid Mechanics 56 (3), 221-251.

Basterfield, R. A., Lawrence, C. J., Adams, M. J., 2005. On the interpretation of orifice extrusion data for viscoplastic materials. Chemical Engineering Science 60 (10), 2599-2607.

Benbow, J. J., 1971. The dependence of output rate on die shape during catalyst extrusion. Chemical Engineering Science 26 (9), 1467-1473.

URL http://www.sciencedirect.com/science/article/pii/ 
Benbow, J. J., Bridgwater, J., 1993. Paste Flow and Extrusion. Clarendon Press.

Benbow, J. J., Oxley, E. W., Bridgwater, J., 1987. The extrusion mechanics of pastes - the influence of paste formulation on extrusion parameters. Chemical Engineering Science 42 (9), 2151-2162.

URL

http://www.sciencedirect.com/science/article/pii/ 0009250987850364

Bryan, M. P., Rough, S. L., Wilson, D. I., 2015. Investigation of static zones and wall slip through sequential ram extrusion of contrasting micro-crystalline cellulose-based pastes. Journal of Non-Newtonian Fluid Mechanics 220, 5768.

Bryan, M. P., Rough, S. L., Wilson, D. I., 2017. Measurement of the wall slip behaviour of a solid granular soap in ram extrusion. Powder TechnologyIn review.

Castro, M., Giles, D. W., Macosko, C. W., Moaddel, T., 2010. Comparison of methods to measure yield stress of soft solids. Journal of Rheology 54 (1), $81-94$.

URL http://scitation.aip.org/content/sor/journal/jor2/54/1/10. $1122 / 1.3248001$

Dimakopoulos, Y., Pavlidis, M., Tsamopoulos, J., 2013. Steady bubble rise in Herschel-Bulkley fluids and comparison of predictions via the augmented Lagrangian method with those via the Papanastasiou model. Journal of Non-Newtonian Fluid Mechanics 200, 34-51.

URL

http://www.sciencedirect.com/science/article/pii/ S0377025712002315

Domanti, A. T. J., Bridgwater, J., 2000. Surface fracture in axisymmetric paste extrusion: An experimental study. Chemical Engineering Research and Design 78 (1), 68-78.

URL http://www.sciencedirect.com/science/article/pii/ S0263876200718661 
Dukic-Ott, A., Thommes, M., Remon, J., Kleinebudde, P., Vervaet, C., 2009.

Production of pellets via extrusion-spheronisation without the incorporation of microcrystalline cellulose: A critical review. European Journal of Pharmaceutics and Biopharmaceutics 71 (1), 38 - 46, special Issue: Solid State and Solid Dosage Forms.

625

URL

http://www.sciencedirect.com/science/article/pii/ S0939641108003184

Götz, J., Buggisch, H., Peciar, M., 1993. NMR imaging of pastes in a ram extruder. Journal of Non-Newtonian Fluid Mechanics 49 (2-3), 251-275.

Hatzikiriakos, S. G., Mitsoulis, E., 2009. Slip effects in tapered dies. Polymer Engineering \& Science 49 (10), 1960-1969.

URL http://dx.doi.org/10.1002/pen.21430

Horrobin, D. J., 1999. Theoretical aspects of paste extrusion. Ph.D. thesis, University of Cambridge.

Horrobin, D. J., Nedderman, R. M., 1998. Die entry pressure drops in paste extrusion. Chemical Engineering Science 53 (18), 3215-3225.

Jay, P., Magnin, A., Piau, J. M., 2002. Numerical simulation of viscoplastic fluid flows through an axisymmetric contraction. Journal of Fluids Engineering 124 (3), 700-705.

Kountouriotis, Z., Georgiou, G. C., Mitsoulis, E., 2014. Numerical study of the combined effects of inertia, slip, and compressibility in extrusion of yield stress fluids. Rheologica Acta 53 (10), 791-804.

URL http://dx.doi.org/10.1007/s00397-014-0803-1

Moyers-Gonzalez, M. A., Frigaard, I. A., 2004. Numerical solution of duct flows of multiple visco-plastic fluids. Journal of Non-Newtonian Fluid Mechanics 645 $122(1), 227-241$.

URL http://www.sciencedirect.com/science/article/pii/ S037702570400206X 
Navier, C. L. M. H., 1823. Mémoire sur les lois du mouvement des fluids. Mem. Acad. Sci. Inst. Fr. 6, 432-436.

Ovenston, A., Benbow, J. J., 1968. Effects of die geometry on extrusion. Transactions of the British Ceramic Society 67, 543-567.

Papanastasiou, T. C., 1987. Flows of materials with yield. Journal of Rheology $31(5), 385-404$.

Patel, M. J., Blackburn, S., Wilson, D. I., 2007. Modelling of paste flows subject to liquid phase migration. International Journal for Numerical Methods in Engineering 72 (10), 1157-1180.

URL http://dx.doi.org/10.1002/nme.2040

Patel, M. J., Blackburn, S., Wilson, D. I., 2017. Modelling of paste ram extrusion subject to liquid phase migration and wall friction. Chemical Engineering Science, - .

URL http://www.sciencedirect.com/science/article/pii/ S0009250917304414

Perrot, A., Lanos, C., Melinge, Y., Estellé, P., 2007. Mortar physical properties evolution in extrusion flow. Rheologica Acta 46 (8), 1065-1073. URL http://dx.doi.org/10.1007/s00397-007-0195-6

Perrot, A., Melinge, Y., Rangeard, D., Micaelli, F., Estellé, P., Lanos, C., 2012. Use of ram extruder as a combined rheo-tribometer to study the behaviour of high yield stress fluids at low strain rate. Rheologica Acta 51 (8), 743-754. URL http://dx.doi.org/10.1007/s00397-012-0638-6

Saramito, P., Roquet, N., 2001. An adaptive finite element method for viscoplastic fluid flows in pipes. Computer Methods in Applied Mechanics and Engineering 190 (40), 5391-5412.

URL http://www.sciencedirect.com/science/article/pii/ S004578250100175X 
Snelling, G. R., Lontz, J. F., 1960. Mechanism of lubricant-extrusion of teflon tfe-tetrafluoroethylene resins. Journal of Applied Polymer Science 3 (9), 257265.

URL http://dx.doi.org/10.1002/app.1960.070030901

Stainsby, R. A. C. R., 1998. Pressure loss equations for laminar and turbulent non-newtonian pipe flow. Journal of Hydraulic Engineering 124 (5), 522-529.

Wildman, R. D., Blackburn, S., Benton, D. M., McNeil, P. A., Parker, D. J., 1999. Investigation of paste flow using positron emission particle tracking. Powder Technology 103 (3), 220-229.

Wilson, D. I., Rough, S. L., 2006. Exploiting the curious characteristics of dense solid-liquid pastes. Chemical Engineering Science 61 (13), 4147-4154. URL http://linkinghub.elsevier.com/retrieve/pii/ S000925090500792X

Zhang, M., Rough, S. L., Ward, R., Seiler, C., Wilson, D. I., 2011. A comparison of ram extrusion by single-holed and multi-holed dies for extrusionspheronisation of microcrystalline-based pastes. International Journal of Pharmaceutics 416 (1), 210-222.

URL http://www.ncbi.nlm.nih.gov/pubmed/21742021 